\title{
Detection of meningeal fibrosis after subarachnoid haemorrhage by assaying procollagen propeptides in cerebrospinal fluid
}

\author{
Juha Sajanti, Kari Majamaa
}

\begin{abstract}
Objective-To study whether meningeal collagen synthesis under normal conditions is reflected in the CSF and whether a meningeal fibroproliferative reaction or fibrosis after subarachnoid haemorrhage can be detected by measuring markers of collagen synthesis in the CSF.
\end{abstract}

Methods-Serum samples and CSF were collected from 56 patients with various neurological symptoms and from nine patients with a recent subarachnoid haemorrhage. The concentrations of the carboxyterminal propeptide of type I procollagen (PICP) and the aminoterminal propeptide of type III procollagen (PIIINP) were measured using radioimmunoassays.

Results-The mean(SD) concentration of PICP was 75.2 (SD 13.6) $\mu \mathrm{g} / 1$ and that of PIIINP 3.56 (SD 0.91) $\mu \mathrm{g} / 1$ in the CSF of the controls, and the $\mathrm{CSF} / \mathrm{serum}$ ratios were 0.74 (SD 0.24) for PICP and 1.34 (SD 0.48) for PIIINP. A 1.4-fold increase in both the PICP $(p=0.001)$ and the PIIINP $(p=0.001)$ concentration was found in patients with a neurological disease and with an abnormal CSF leucocyte count or protein concentration. In eight patients with a recent subarachnoid haemorrhage the PICP was 5.9 -fold higher $(p<0.001)$ and the PIIINP concentration 7.7-fold higher $(p<0.001)$ than that in the controls, whereas no difference was found in the serum values. Similar high concentrations were also found in a patient from whom the CSF sample was obtained before operation for aneurysm.

Conclusions-The intrathecal compartment is a site for active collagen synthesis under normal conditions. The synthesis rate is markedly increased in patients with a recent subarachnoid haemorrhage, suggesting a fibroproliferative reaction or fibrosis. Assays of procollagen propeptides may be useful in the clinical diagnosis of meningeal fibrosis and their use may enable the identification of diseases and symptoms aetiologically related to meningeal fibrosis.

(F Neurol Neurosurg Psychiatry 1999;67:185-188)

Keywords: meninges; collagen; CSF protein; laboratory analysis

A significant proportion of the extracellular matrix of the dura and the arachnoid is composed of different collagens ${ }^{1}$ that are synthesised by dural fibroblasts or leptomeningeal cells. ${ }^{2}$ Mesenchymal cells such as these may be provoked by noxious stimuli to increase their synthesis of the extracellular matrix components, resulting in fibrosis. Meningeal fibrosis has been seen histologically in experimental animals after the injection of blood into the subarachnoid space ${ }^{34}$ and in patients who died from subarachnoid haemorrhage. ${ }^{5}$ These findings suggest that the meninges are a site for a fibroproliferative reaction as well as fibrosis in subarachnoid haemorrhage. Clinically, however, meningeal fibrosis is a poorly defined entity, although diffuse meningeal enhancement seen on MRI may suggest the diagnosis. ${ }^{6}$

The synthesis of collagens involves many enzyme catalysed modification reactions both inside and outside the cell. ${ }^{7}$ The activity of some of these enzymes in tissue samples or the contents of some of the reaction products in tissue fluids have been used as an indicator of the rate of collagen biosynthesis both in normal conditions and in fibrosis. ${ }^{8}$ Useful clinical markers of collagen synthesis seem to be measurement of the concentrations of the C-terminal propeptide of type I procollagen (PICP) and the N-terminal propeptide of type III procollagen (PIIINP) in serum. ${ }^{9}$

Analysis of collagen synthesis in CSF would introduce higher sensitivity in the diagnostics of meningeal fibroproliferative states compared with imaging studies, but the applicability of this approach has not been assessed. Therefore, we evaluated practical methods for studying the rate of collagen synthesis in the intrathecal compartment. We measured in the CSF the activity of two enzymes that are involved in the intracellular processing of collagens and the concentration of two procollagen propeptides that are released into the extracellular space during biosynthesis.

\section{Patients and methods}

PATIENTS

A CSF sample and a parallel serum sample from 32 consecutive patients undergoing a diagnostic spinal tap was collected. After the diagnostic evaluation had been completed, the patients were considered for inclusion in one of two clinically defined subgroups. The first subgroup-group 1 controls-comprised 21 patients (headache, six; dizziness or vertigo, five; sensory symptoms, three; depression, two; psycho-organic syndrome, one; memory impair- 
Table 1 Clinical features of patients with subarachnoid haemorrhage (group 2)

\begin{tabular}{lll}
\hline & Median & Range \\
\hline Clinical grade on admission & 2 & $1-3$ \\
$\quad$ Hunt and Hess & 18 & $2-22$ \\
$\quad$ Amount of blood in CT & 4.8 & $1.9-132$ \\
Clinical events after the bleeding & 3.5 & $0.5-8$ \\
$\quad$ First CT (h) & 14 & $8-25$ \\
Aneurysm operation (days) & & \\
CSF sample for analysis (days) & & \\
\hline
\end{tabular}

An aneurysm was found and operated on in each patient (anterior communicating artery, four; medial cerebral artery, four; posterior cerebral artery, one).

${ }^{\star} \mathrm{CSF}$ sample from one patient was obtained before aneurysm operation at day 18 after the bleeding. This patient is not included in the data on the timing of the aneurysm operation.

ment, one; amaurosis, one; muscular twitching, one; pupillary anisocoria, one). The second subgroup-group 1 patients-comprised 11 persons with a neurological disease or neurological symptoms and with an abnormal CSF leucocyte count or protein content (radiculopathy, two; acute polyradiculitis, two; remote CNS infection, two; multiple cranial mononeuropathy, one; postoperative state of lumbar disc disease, one; spinal stenosis, one; pulmonary sarcoidosis and headache, one; headache, one).

Group 2 comprised nine patients with a recent subarachnoid haemorrhage (table 1). The clinical grade of the patients was evaluated on admission using a validated rating scale ${ }^{10}$ and the amount of blood was visually graded on the first CT. ${ }^{11}$ A CSF sample and a parallel serum sample were obtained between days 8-25 after the haemorrhage. In one case the sample was obtained before operation for aneurysm at day 18 after the haemorrhage.

The study protocol has been approved by the ethics committee of the Medical Faculty of the University of Oulu. The samples were obtained with the informed consent of the patients.

METHODS

The CSF and blood samples were centrifuged at $3000 \mathrm{rpm}$ for 10 minutes and the supernatant was stored at $-75^{\circ} \mathrm{C}$ until assayed. The cell count of the CSF was determined as part of the routine clinical chemical analysis of the CSF. The total protein content was determined using a colorimetric assay. ${ }^{12}$
Preliminary studies on the CSF and serum samples from 24 separate patients with a neurological disease and with abnormal CSF suggested that the amount of aminoterminal propeptide of type III procollagen (RIA-gnost PIIIP; Behringwerke, Marburg, Germany) and the activity of collagen glucosyltransferase were readily measurable in the $\mathrm{CSF}$, whereas the activity of prolyl 4-hydroxylase was undetectable. The data also suggested that the assay of the procollagen propeptide is more sensitive than that of collagen glucosyltransferase. Therefore, the studies reported here were carried out using specific radioimmunoassays for both the aminoterminal propeptide of type III procollagen (PIIINP) and for the carboxyterminal propeptide of type I procollagen (PICP) (Orion Diagnostica, Turku, Finland).

STATISTICAL ANALYSIS

The normality of the distributions was verified first by using both the Kolmogorov-Smirnov test with Lilliefors' significance correction and the Shapiro-Wilk test. In most of the groups the values were normally distributed and therefore statistical analysis was carried out by one way analysis of variance (ANOVA) to detect the difference between the groups and subsequent comparisons between the two groups were made by paired or unpaired $t$ tests, as appropriate. Pearson's correlation coefficient was calculated when the concentrations of the propeptides in the CSF were compared with the total protein.

\section{Results}

CONCENTRATIONS OF PICP AND PIIINP IN THE CSF AND SERUM OF THE CONTROLS AND PATIENTS WITH NEUROLOGICAL SYMPTOMS AND WITH AN ABNORMAL CSF

We assayed CSF and serum samples for the concentrations of PICP and PIIINP from 32 patients (group 1). The concentration of PICP in the CSF of group 1 controls was 75.2 (13.6) $\mu \mathrm{g} / 1$ and that of PIIINP was $3.56(0.91) \mu \mathrm{g} / 1$ (table 2). We did not find any changes with age or sex in these concentrations. The CSF/serum ratio was 1.34 (95\% confidence interval $(95 \%$ CI) 1.12-1.56) for PIIINP, and the corre-

Table 2 Clinical features of patients in group 1 and group 2 and their PICP and PIIINP concentrations in CSF and serum

\begin{tabular}{|c|c|c|c|c|}
\hline & \multicolumn{4}{|l|}{ Patient group } \\
\hline & $\begin{array}{l}\text { Group } 1 \text { controls } \\
\text { Mean (SD) }\end{array}$ & $\begin{array}{l}\text { Group } 1 \text { patients } \\
\text { Mean (SD) }\end{array}$ & $\begin{array}{l}\text { Group } 2 \text { patients } \\
\text { Mean (SD) }\end{array}$ & Range \\
\hline Clinical description & No CNS disease & $\begin{array}{l}\text { Neurological disease } \\
\text { with abnormal CSF }\end{array}$ & Recent SAH & \\
\hline Men/women (n) & $9 / 12$ & $7 / 4$ & $5 / 4$ & \\
\hline Age $(y)$ & $40.9(14.4)$ & $44.3(13.0)$ & $46.4(9.1)$ & \\
\hline CSF leucocytes $\left(\times 10^{9} / 1\right)$ & 1 ; range $0-3$ & 1 ; range $0-50$ & ND & \\
\hline $\mathrm{CSF}$ protein $(\mathrm{mg} / \mathrm{l})$ & $320(115)$ & $741(397) \dagger$ & $995(514)$ & 377-1974 \\
\hline \multicolumn{5}{|l|}{ PICP } \\
\hline In CSF $(\mu \mathrm{g} / \mathrm{l})$ & $75.2(13.6)$ & $103(19.2) \ddagger$ & $447(222)$ & $175-898$ \\
\hline In serum $(\mu \mathrm{g} / \mathrm{l})$ & $110(37.3)$ & $126(35.0)$ & $77.7(33.9)^{\star}$ & $43.9-144$ \\
\hline $\mathrm{CSF} /$ serum ratio & $0.74(0.23)$ & $0.84(0.25)$ & $5.96(3.72)$ ฯ & $1.41-13.9$ \\
\hline \multicolumn{5}{|l|}{ PIIINP } \\
\hline In CSF $(\mu \mathrm{g} / 1)$ & $3.56(0.91)$ & $5.14(1.65) \ddagger$ & $27.5(20.8)$ ฯ & $11.1-74.6$ \\
\hline In serum $(\mu \mathrm{g} / \mathrm{l})$ & $2.85(0.78)$ & $3.41(1.23)$ & $2.22(1.40)$ & $1.05-5.52$ \\
\hline $\mathrm{CSF} /$ serum ratio & $1.34(0.48)$ & $1.70(1.11)$ & $15.2(12.1)$ ฯ & $3.87-42.3$ \\
\hline \multicolumn{5}{|l|}{ PICP/PIIINP ratio } \\
\hline In CSF & $21.7(3.11)$ & $20.9(4.11)$ & $18.5(6.21)$ & $12.0-29.7$ \\
\hline In serum & $42.2(20.3)$ & $41.6(18.8)$ & $39.1(11.7)$ & $22.2-57.9$ \\
\hline
\end{tabular}

${ }^{\star} \mathrm{p}<0.05 ; \mathrm{tp}<0.01 ; \neq \mathrm{p}=0.001 ; \uparrow \mathrm{p}<0.001 ; \mathrm{ND}=$ not determined. 
sponding ratio for PICP was 0.74 (95\% CI $0.63-0.85)$. The PICP/PIIINP ratio in the serum was twofold higher than that in the CSF. There was a significant correlation of PICP in the CSF with PIIINP in the CSF $(r=0.832$; $\mathrm{p}<0.001)$. On the other hand, the CSF concentrations of the two propeptides did not correlate with the total CSF protein concentration or to the serum concentrations of the respective propeptides.

Group 1 patients included 11 persons with a neurological disease or neurological symptoms and with an abnormal CSF leucocyte count or protein content (table 2). The concentrations of both PICP and PIIINP in the CSF of these patients were 1.4-fold higher than those of the controls $(p=0.001)$. We did not find differences in the serum values nor in the various ratios that were calculated (table 2).

MARKEDLY INCREASED INTRATHECAL COLLAGEN SYNTHESIS IN PATIENTS WITH A RECENT SUBARACHNOID HAEMORRHAGE

Markedly increased concentrations of PICP and PIIINP in the CSF were found in nine patients with a recent subarachnoid haemorrhage (group 2 ), whereas no increases were found in the corresponding serum concentrations (table 2 ). The mean concentration of PICP in the CSF of group 2 was 5.9-fold higher and that of PIIINP 7.7-fold higher than in controls. The corresponding $\mathrm{CSF} /$ serum ratios were increased in a similar manner. The CSF sample from one patient in group 2 was obtained before aneurysm operation and similar high concentrations of the propeptides were also found in this patient. The PICP/PIIINP ratio in the CSF and the serum was not different between group 2 and the controls. The increase in the total protein content of CSF was only 3.1-fold in group 2 and, furthermore, we did not find a correlation between the two propeptide concentrations and the total protein concentration.

\section{Discussion}

The propeptides of type I and type III procollagens were found to belong to a group of rare proteins, the concentration of which is disproportionately high in the CSF compared with that in the serum. In general, the CSF/serum ratios of the major serum proteins are low-for example, that of albumin is around 1:200-due to the function of the blood-CSF barrier. Proteins with a disproportionately high CSF concentration include transthyretin (prealbumin), prostaglandin $\mathrm{D}$ synthase (the $\beta$-trace protein), cystatin $C$ (the $\gamma$-trace protein), and transferrin. ${ }^{13}$ With the exception of transferrin, ${ }^{14}$ active synthesis of these proteins in the choroidal epithelium or elsewhere in the CNS has been shown in humans. ${ }^{15-17}$ We calculated that passive diffusion across the bloodCSF barrier could account for less than $1 \%$ of the procollagen propeptides in the CSF suggesting an active collagen turnover in the intrathecal compartment.

The diagnosis of meningeal fibrosis is usually a radiological or histological one, and markers of collagen metabolism have been seldom measured in the CSF. We found minor but sig- nificant increases in PICP and PIIINP concentrations in the CSF of patients with an abnormal CSF leucocyte count or protein content but without clinical evidence for arachnoiditis. Similarly, minor increases have been found in children after the initiation of intrathecal methotrexate treatment for leukaemia, a treatment modality that may induce an arachnoiditis. $^{18}$ By contrast, markedly increased concentrations of both propeptides were found in the CSF of patients with recent subarachnoid haemorrhage. No increase was found in the serum concentrations of the propeptides, suggesting that they were synthesised in situ.

The increase in the CSF propeptide concentrations is most likely related to the haemorrhage itself and not to the effects of craniotomy. We found that the propeptide concentrations were equally high in a patient from whom the CSF sample was obtained before operation for aneurysm at day 18 after the bleeding. Furthermore, we have shown that injection of autologous blood into the cisterna magna through a burr hole leads to an increase in meningeal collagen synthesis in rats, whereas a burr hole without injection of foreign material does not have that effect (J Sajanti et al, unpublished data).

The CSF samples were obtained from the patients with subarachnoid haemorrhage on days 8-25 after the haemorrhage. The biochemical changes of fibrosis are time dependent, being most prominent between weeks 1 and 2 after the injury, when an increase in the collagen specific mRNAs ${ }^{19-21}$ and an increase in the rate of collagen biosynthesis ${ }^{22} 23$ may be detected. A postmortem study has disclosed that collagen fibres appear in the arachnoid granulations and in the subarachnoid space during the second and third week after the subarachnoid haemorrhage. ${ }^{5}$ Interestingly, we have found that deposition of type I collagen in rat meninges occurs on week 3 after experimental subarachnoid haemorrhage (J Sajanti et al, unpublished data). The markedly increased concentrations of the procollagen propeptides in the CSF of patients with subarachnoid haemorrhage are, therefore, in accordance with an active phase of fibrosis.

\section{Conclusions}

The intrathecal compartment is a site for active collagen turnover and an intrathecal fibroproliferative reaction or fibrosis follows subarachnoid haemorrhage. The measurement of PICP or PIIINP in CSF is a practicable method for the biochemical determination of collagen turnover and provides the first chemical assay for the assessment of meningeal fibrosis. Assays of procollagen propeptides may enable the identification of diseases and symptoms aetiologically related to meningeal fibrosis.

This study was supported in part by grants from the Maire Taponen Foundation.

\footnotetext{
1 Haines DE. On the question of a subdural space. Anat Rec 1991;230:3-21.

2 Rutka JT, Giblin J, Dougherty DV, et al. An ultrastructural and immunocytochemical analysis of leptomeningeal and
} 
meningioma cultures. F Neuropathol Exp Neurol 1986;45: 285-303.

3 Suzuki S, Ishii $M$, Ottomo $M$, et al. Changes in the subarachnoid space after subarachnoid haemorrhage in the dog: scanning electron microscopic observation. Acta Neudog: scanning electron microsc
rochir (Wien) 1977;39:1-14.

4 Suzuki S, Ishii M, Iwabuchi T. Post-hemorrhagic subarachnoid fibrosis in dogs. Scanning electron microscopic observation and dye perfusion study. Acta Neurochir (Wien) 1979;46:105-17.

5 Motohashi O, Suzuki M, Shida N, et al. Subarachnoid hemorrhage induced proliferation of leptomeningeal cells and deposition of extracellular matrices in the arachnoid granulations and subarachnoid space. Immunohistochemical study. Acta Neurochir (Wien) 1995;136:88-91.

6 Meltzer CC, Fukui MB, Kanal E, et al. MR imaging of the meninges. Part I. Normal anatomic features and nonneoplastic disease. Radiology 1996;201:297-308.

7 Prockop DJ, Kivirikko KI. Collagens: molecular biology, diseases, and potentials for therapy. Annu Rev Biochem 1995;64:403-34.

8 Annala AP, Risteli L, Koivukangas V, et al. Measurement of collagen metabolism in skin diseases. A review of old and new techniques and their clinical applications. Eur $\mathcal{F}$ Dermatol 1993,3:696

9 Risteli J, Risteli L. Analysing connective tissue metabolites in human serum. Biochemical, physiological and methodological aspects. F Hepatol 1995;22 (suppl 2):77-81.

10 Hunt WE, Hess RM. Surgical risk as related to time of intervention in the repair of intracranial aneurysms. Neurosurgery $1968 ; 28: 14-20$.

11 Hijdra A, Brouwers PJ, Vermeulen M, et al. Grading the amount of blood on computed tomograms after subarachnoid hemorrhage. Stroke 1990;21:1156-61.

12 Bradford MM. A rapid and sensitive method for the quantitation of microgram quantities of protein utilizing the principle of protein-dye binding. Anal Biochem 1976;72:248ciple

13 Thompson EJ, Keir G. Laboratory investigation of cerebrospinal fluid proteins. Ann Clin Biochem 1990;27:425-35.
14 Tu GF, Achen MG, Aldred AR, et al. The distribution of cerebral expression of the transferrin gene is species specific. f Biol Chem 1991;266:6201-8.

15 Herbert J, Wilcox JN, Pham KTC, et al. Transthyretin: a choroid plexus-specific transport protein in human brain. Neurology 1986;36:900-11.

16 Blodorn B, Mader M, Urade Y, et al. Choroid plexus: the major site of mRNA expression for the $\beta$-trace protein prostaglandin D synthase) in human brain. Neurosci Lett 1996;209:117-20.

17 Lignelid $\mathrm{H}$, Collins VP, Jacobsson B. Cystatin C and transthyretin expression in normal and neoplastic tissues of the human brain and pituitary. Acta Neuropathol 1997;93: 494-500.

18 Vainionpää L, Risteli L, Lanning M, et al. Carboxyterminal propeptide of type I procollagen in cerebrospinal fluid in childhood and in children with leukemia undergoing intrathecal treatment. Clin Chem 1991;37:1365-9.

19 Raghow R, Lurie S, Seyer JM, et al. Profiles of steady state levels of messenger RNAs coding for type I procollagen, elastin, and fibronectin in hamster lungs undergoing bleomycin-induced interstitial pulmonary fibrosis. F Clin Invest 1985;76:1733-9.

20 Ala-Kokko L, Pihlajaniemi T, Myers JC, et al. Gene expression of type I, III and IV collagens in hepatic fibrosis induced by dimethylnitrosoamine in the rat. Biochem 7 1987;244:75-9.

21 Scharffetter K, Kulozik M, Stolz W, et al. Localization of collagen $\alpha 1$ (I) gene expression during wound healing by in situ hybridization. F Invest Dermatol 1989;93:405-12.

22 Clark JG, Overton JE, Marino BA, et al. Collagen biosynthesis in bleomycin-induced pulmonary fibrosis in hamsters. F Lab Clin Med 1980;96:943-53.

23 Risteli J, Kivirikko KI. Intracellular enzymes of collagen biosynthesis in rat liver as a function of age and in hepatic injury induced by dimethylnitrosamine. Changes in prolyl hydroxylase, lysyl hydroxylase, collagen galactosyltransferase and collagen glucosyltransferase activities. Biochem $\mathcal{f}$ 1976;158:361-7. 